\title{
Reading Specialists’ Perceptions and Pedagogical Practices towards Struggling Readers
}

\author{
Alma Williams ${ }^{1} \&$ Evan Ortlieb ${ }^{2, *}$ \\ ${ }^{1}$ Creativity, Innovation, and Design Coach, Corpus Christi Independent School District, \\ Corpus Christi, Texas 78403, USA \\ ${ }^{2}$ Senior Lecturer in Primary and Literacy Education, Monash University, Faculty of \\ Education, Frankston, Victoria 3199, Australia \\ *Corresponding author: Faculty of Education, Monash University, Melbourne, Australia. \\ Tel: 61-3-9904-4661 E-mail: Evan.ortlieb@monash.edu
}

Received: January 5, 2014 Accepted: May 16, $2014 \quad$ Published: May 29, 2014

doi:10.5296/ije.v6i2.5425ＵRL: http://dx.doi.org/10.5296/ije.v6i2.5425

\begin{abstract}
Though concentrated efforts have focused on scientifically based instructional skills compulsory for reading development, they have failed to address the relationship between reading attitude and reading performance. Literacy experts have widely acknowledged the importance of ongoing efforts towards instilling and maintaining a positive attitude and motivation for reading, especially as it pertains to struggling readers. Investigators sought to examine reading specialists' perspectives of struggling readers' attitudes towards reading and their teaching practices used to bolster students' attitudes and abilities to read. This case study investigation involved 10 reading specialists who reported explicit instruction of both decoding and comprehension skills was the most common contributor to students' negative attitudes about reading. Classroom teachers can combat this trend by implementing an array of reading strategies and providing more student-centered interventions from early grades through junior high school.
\end{abstract}

Keywords: reading specialist, reading attitude, struggling readers, motivation 


\section{Introduction}

Many teachers report that seeing a child develop reading proficiencies is one of the most fulfilling experiences of being an educator; however, those instances are often stifled based on a number of factors. Despite federal initiatives towards implementing more effective reading instruction programs (No Child Left Behind Act of 2001; Reading First), student scores have remained relatively stable from 1992-2011 (National Assessment of Educational Progress, 2011). These scientifically based actions focused on instructional skills compulsory for reading development, though failed to address the relationship between reading attitude and reading performance.

Literacy experts have widely acknowledged the importance of ongoing efforts towards instilling and maintaining a positive attitude and motivation for reading, especially as it pertains to struggling readers (Edmunds \& Bauserman, 2006; Gambrell, 1996; Morgan \& Fuchs, 2007; Wigfield \& Guthrie, 1997). Educators are keenly aware that negative attitudes towards reading persist when text reading is too challenging. Individuals engage in practices that bring pleasure and/or feelings of success whether in academic or social activities. Hence, many struggling readers read less often than their higher performing classmates (Ganske, Monroe, \& Strickland, 2003). If advancement in literacy is to be attained, it is fundamental to improve struggling readers' attitudes towards reading (Guthrie, Coddington, \& Wigfield, 2009; Marinak \& Gambrell, 2010). Teachers of struggling readers must be included in research to inform curricular planning and instructional decisions if improvements are to be made.

Investigators sought to examine reading specialists' perspectives of struggling readers' attitudes towards reading, and their teaching practices used to bolster students' attitudes and abilities to read. Are these unenthusiastic attitudes a result of unpleasant reading experiences during early childhood years? Were students negatively influenced by instructional methods? Exploring the roots of students' loss of enthusiasm for reading is vital towards reconnecting children with high quality literature and enjoyable learning opportunities.

\section{Theoretical Framework}

This investigation is grounded in interpretive theories that maintain the basic notion that there are multiple truths (Berger \& Luckmann, 1966). Crotty (1998) purports, "Truth, or meaning, comes into existence in and out or our engagement with the realities in our world . . . it is clear that different people may construct meaning in different ways, even in relation to the same phenomenon" (p.8). Unlike the positivist framework, interpretivism seeks to understand and explain human and social reality — an understanding that is different for every individual person (Bhattacharya, 2007; Smith, 1983).

This study is supported by Dilthey's (1972) notion of hermeneutics as a method for research involving human sciences. Using this lens, we understand ourselves only by means of objectifications whereas earlier lived experiences had been assumed to provide us an understanding of ourselves. Hermeneutics implicitly underpins this qualitative inquiry, where 
dialogue and interpretation are necessary for this critical approach (Kinsella, 2006). Bontekoe (1996) furthers that the interpreter must not only recognize the significance of observed phenomenon but also the way in which those items relate to one another.

Through interviewing reading specialists, they can share their lived experiences with struggling readers revealing their own personal observations and individual truths. Teachers' attitudinal stances can include asking, believing, presuming, claiming, taking pleasure in, approving, liking, wishing, desiring, and willing. Investigating these teachers' unique complexities and making sense of their responses is central to complete the hermeneutic cycle- understanding of the whole (Schwandt, 2001).

\section{Review of Literature}

\subsection{Interest/Attitudes in Reading}

Students' attitudes toward reading and their declining interest in reading are concerns among reading educators and researchers (Guthrie \& Wigfield, 2000; Pitcher, Albright, DeLaney, Walker, et al., 2007) as reading engagement across all grade levels has decreased nationally. Ivey and Broaddus (2001) suggest this decline in positive attitudes toward reading may be caused by the unfortunate but repeated mismatch of students' needs and the reading instruction provided to them. After all, motivation, learning, and reading achievement are intertwined (Hughes, Brooker, Gambrell, \& Foster, 2011). Positive attitudes increase learning, whereas poorly developed and inadequately delivered instruction reduces motivation.

The relationship between reading attitude and achievement is reciprocal. Guthrie and Wigfield (2000) found that there is a greater correlation between reading attitudes and reading comprehension than between reading comprehension and other demographic markers such as gender, income, and ethnicity. Positive reading attitudes and a learner's internal motivation to read are resources that often empower students to overcome traditional barriers to successful reading (Brophy, 1999). Furthermore, Brophy (1999) considers the possibility that attitude contributes to the development of schemas, and a positive attitude can lead to more effective use of the cognitive retrieval systems necessary for the reading process. Therefore, students with positive attitudes towards reading are thoughtful readers (Applegate \& Applegate, 2010) who are more likely to actively engage in reflective and critical thinking processes as they read.

Stanovich (1986) identified this cycle as the "Matthew Effect," where good readers enjoy reading, develop positive attitudes towards reading, and continue to read more books. This creates a positive spiral in which student achievement and motivation thrive. Unfortunately, the opposite is also true. Struggling readers commonly do not enjoy reading and develop negative attitudes which cause them to cease reading. The challenge for reading educators is to provide instruction that breaks this cycle by offering positive reading experiences to those students who view reading negatively. 
Increasing student reading attitude relies upon teachers being deeply attentive to students' personal needs and uses of literacy as well as to what students deem important as potential readers (Nichols, Dagen, \& Rinehart, 2011). Students who recognize reading as a meaningful activity in their lives rather than merely a school-related pursuit become motivated to read successfully. So, reading educators must evaluate and address attitude and motivation to read as a preliminary step to improve reading performance (Hughes, Brooker, Gambarell, \& Foster, 2011). Affective reading instruction cannot ignore students' attitudes toward reading; it must target attitudes with the intent to increase student motivation to read.

One way of building positive attitudes is to broaden definitions of acceptable reading materials used for instructional purposes. Pitcher and her colleagues (2007) recommend that teachers include digital texts, popular culture/music, and newspapers/magazines in reading instruction. Students frequently perceive these sorts of texts as authentic reading materials, facilitating the shift from inactive readers to critical consumers of a wide variety of texts.

\subsection{Specialists’ Reading Practices}

Solely emphasizing a positive attitude towards reading is not sufficient for maximizing student reading achievement. Paired with a focus on reading attitudes, educators must employ instructional practices they know to be effective in teaching students to read. In doing so, teachers provide quality learning experiences that increase reading achievement. According to Vacca and Vacca (2008), "teachers who provide choices, challenging tasks, and collaborative learning experiences increase students' motivation to read and comprehend” (p. 17). Effective reading instruction, including remediation, offers struggling readers: opportunities to read both familiar and new high quality literature; activities to practice word analysis and letter-sound relationships, if necessary; writing activities; and active engagement in learning processes (Wasik, 1998).

In developing effective programs for students who struggle with reading, the importance of reading materials cannot be ignored. A variety of high-quality literature is essential to increase motivation and reading achievement (Reis, McCoach, Little, Muller, \& Kaniskan, 2011). Books should be of high interest to the student and self-selected when possible (Ortlieb, 2010). Reading materials should also be above students' current independent reading levels, providing an appropriate challenge that does not frustrate the reader.

Struggling readers also need instruction in thinking/comprehension strategies (Vaughn, Klinger, Swanson, Boardman, Roberts, Mohammed, \& Stillman-Spisak, 2011). The comprehension strategies associated with improved results in reading achievement include: using strategies to figure out the meaning of unknown words; activating prior knowledge; self-monitoring comprehension during reading; creating graphic organizers to structure notes on texts; questioning what is being read; understanding narrative and expository text structures; and using cooperative learning to increase engagement (NICHD, 2000; Tovani, 2000).

Instruction of these comprehension strategies ideally follows a release of responsibility model (Kamil, 2004; McKeown et al., 2009; Neufeld, 2006; Pearson \& Gallagher, 1983; Tovani, 
2000). Reis and colleagues (2011) recommend beginning with teacher demonstrations of reading strategies and self-regulation skills, often modeled with a read-aloud or think-aloud. After suitable modeling, the emphasis becomes guided and focused on the self-regulation of reading appropriately challenging books. Teachers work with students on skill instruction such as predicting, inferencing, and making connections, as well as discussing textual content. As students become more advanced readers, it is beneficial to provide opportunities for students to engage in a wide variety of enrichment activities to extend their reading and pursue interests through collaborative discussions, advanced questionings, and creative projects requiring the use of thinking skills.

Whereas Vaughn and her colleagues (2011) as well as others (e.g., Baker, 2002; Block, Gambrell, \& Pressley, 2002; NICHD, 2000) posit that explicit instruction and practice in comprehension strategies result in improvements in reading comprehension. McKeown, Beck, and Blake (2009) contend that a well-constructed discussion about a text's content is a more effective strategy for reading instruction in that it focuses directly on the crux of the matter. Rather than students focusing on completing certain thinking strategies, they concentrate solely on understanding what a text is communicating. In this way, teaching comprehension strategies becomes secondary to the construction of a text's meaning, avoiding the issue of students becoming fixated on comprehension strategies rather than a text's content.

When teaching struggling readers, even during intervention support, it is important to remember the end and not focus on the means (Kamil, 2004). Effective reading instruction improves students' reading attitudes and comprehension so that they may read to learn and read for enjoyment (Ortlieb, Grandstaff-Beckers, \& Cheek, 2012). Appropriate reading instruction and remediation is framed on the notion of teaching students to read authentically.

\section{Methods}

This case study investigating reading specialists' perspectives of struggling readers' attitudes was guided by Johnson and Christensen's (2008) case study model, or "research that provides a detailed account and analysis of one or more cases" (p. 406). Each of these different kinds of cases can be considered a 'bounded system' in the sense that it comprises a complex of interrelated elements or characteristics that has clearly identifiable boundaries (Stake, 2006). This study's instrumental purpose (Stake, 1995) was to better understand struggling readers' attitudes towards reading from the perspectives of their reading specialists. A case study was selected because it does not act as a means to an end nor attempt to generalize, but rather examine the intrinsic uniqueness of the individual case in depth for its own sake (Yin, 2002).

\subsection{Data Collection}

The research team carefully proceeded through the following procedural steps: (1) developing interview questions (see Figure 1); (2) selecting 10 participants for inclusion; (3) piloting interview questions and in turn, refining them; (4) conducting formal and informal interviews/record data; (5) writing in a journal as part of the analysis of interviews using multiple researchers; (6) identifying patterns/themes that emerge from interviews; and (7) 
triangulating data via trend analysis and a bracketing interview.

Ten reading specialist participants were selected based on convenience sampling; these specialists worked with struggling readers in a South Texas school district. Inter-rater reliability was utilized to preserve the authenticity of the data analysis and minimize researcher bias.

1) Tell me what you do when a struggling reader reads something he/she absolutely hated.

2) Discuss the steps you take or advise your teachers to take when helping a struggling reader complete as assigned reading lesson.

3) Tell me what you have observed happens when a struggling reader is trying to read.

4) Share with me how you handled helping a struggling reader who got stuck when reading.

5) Share with me the steps you tell a struggling reader to take when they have read their reading subjects books.

6) Give me an example of the types of books struggling readers really dislike and why you think they dislike those books.

7) Which grade levels do you think reading teachers should limit interacting and discontinue providing guided reading in the classrooms?

Figure 1. Formal interview questions

\subsection{Data Analysis}

Multiple investigators transcribed data collected from the interviews (see Figure 2). Codes were assigned with labels attached to words, phrases, and paragraphs to assign a unit of description, meaning, inference, or relationship (Bhattacharya, 2007). Line-by-line coding was utilized before making member check adjustments. Data were then chunked into workable units to allow for the combination of similar units of meaning, description, or inferences to analyze data and answer research questions posed in the study (Bhattacharya, 2007). 
Interviewer: Tell me what you do when a struggling reader reads something he/she absolutely hated.

Participant: I think I would definitely allow them to voice their opinion about what they did not like about the book, passage, etc...

I would ask them to discern why they hated it.

For example:

a. It was too difficult to read. The decoding process was so difficult that it took away from the enjoyment of reading.

b. It was not interesting. Why?

c. The content was confusing or hard to understand. What parts were confusing?

d. I disagree with the content. Why?

e. I could not relate to the character, content, etc...

This would allow the student to try to understand why some reading tasks aren’t particularly enjoyable and allow them to take an objective look at why they dislike the assignment rather than just a blanket statement such as “This was dumb. This was boring.”

f. I would discuss with them that we don't always enjoy everything we are asked to read. I would give them some personal examples of books or material that I don't particularly care to read or that were difficult for me to understand. I would let them know it is perfectly normal to dislike certain reading assignments, books, etc...

Interviewer: Thanks for your response. So, do you think struggling readers really don't have a negative attitude towards reading itself, but instead towards the process some of them have to endure just to read?

Participant: $\quad$ I have no way of knowing for sure, but I would bet that it has more to do with the process. The struggling reader's (dyslexic's) process to decode a word is much more involved than a natural reader's is. I think most struggling readers would not hate to read if their brain processed the words quickly and easily.

Figure 2. Transcribed interview with a reading specialist

Next, units of meaning were organized into categories and identified with themes from the categories. Following Shank's (2006) general structure of inductive analysis, researchers "converse" with the data and find out what the data is "telling" the researcher. This process includes: making decisions about the general approach to use for data analysis; choosing ways to organize the data; and attempting to identify what the data is "telling" at a larger level. These themes and theories, along with artifacts, were documented throughout the process of the study. Debriefing preceded the final data analysis to provide an opportunity to ask all remaining questions regarding the reading specialists' perceptions and experiences with struggling readers and their attitudes towards reading.

The transcripts were interpreted through codes before being placed into categories, and finally into developed themes including insights from the categories using Spradley's (1980) procedures for domain analysis (see Figure 3) and a taxonomic analysis (see Figure 4). Finally, investigators identified the strategies used by reading specialists with struggling readers throughout the school district. 
$>$ Reading Specialist

- $\quad$ Tell me the steps you follow when helping struggling readers complete an assigned reading lesson.

- $\quad$ Share how you handle helping struggling readers when they get stuck?

- $\quad$ Share some graphic organizers you use with struggling readers.

Presumed interventions by the classroom teacher

- $\quad$ Realistically, which interventions do you think the classroom teachers provide?

$>\quad$ "In a perfect world" interventions by the classroom teacher

- Which interventions would the reading specialist like to see classroom teachers use?

$>$ Reasons why struggling readers hate assigned texts

- Do you think struggling readers really don't have negative attitudes towards reading, but instead towards the reading process they have to endure?

Dbserved behavior of struggling readers when reading

- What behaviors have you observed when struggling readers are trying to read?

$>$ Techniques used when struggling readers hate the text

- What do you do when struggling readers read something they hate

Figure 3. Spradley's (1980) procedures for domain analysis 


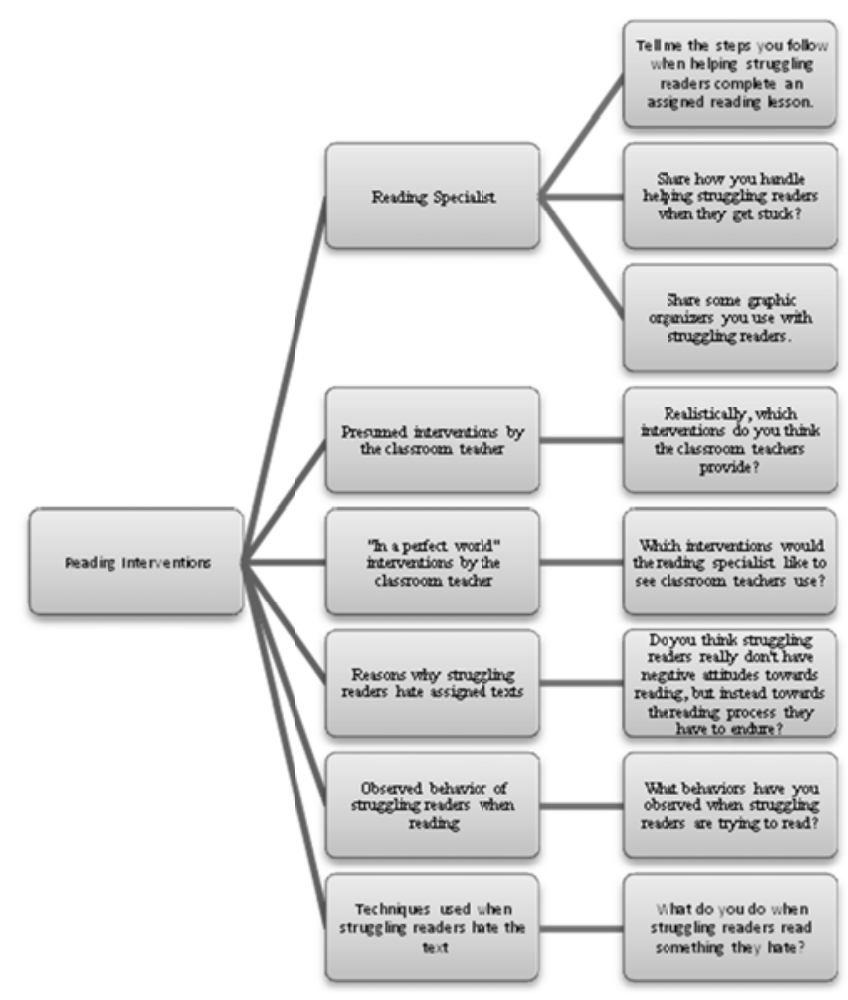

Figure 4. Spradley’s (1980) taxonomy analysis

\section{Findings}

Through analyzing the interviews and collected data, it was evident that the process of decoding words as well as comprehension skill instruction were the most common contributors to students' negative attitudes about reading. The skills-based process was tedious, seemed unnatural, and resisted by readers, according to numerous reading specialists. Students were perceived to dislike the steps involved in becoming more proficient readers, whereas if they had to read, they would prefer to read something "easy" for them (independent level). Students selected shorter texts or not reading at all, utilizing an avoidance strategy commonly found in struggling readers (Baker \& Wigfield, 1999; Powers, 1981), as many lack self-efficacy, or the belief that one can be successful at reading (Bandura, 1997; Schunk \& Zimmerman, 1997).

Though reading specialists provide numerous interventions, guided reading prevailed as the most common intervention for students in grades K-5. Yet, there appears to be a discrepancy amongst teachers regarding when to limit teacher interaction and guided reading practices. Half of the reading specialists believed that teacher interaction and guided reading should be provided throughout upper elementary and into junior high classrooms. Their contention was that in order for struggling readers to read text, they must possess a range of strategies necessary to apply, therefore, making the process of reading a difficult task for struggling readers to master and causing negative attitudes towards the process, not towards reading itself. This may factor into why the low achieving students in junior high dislike reading, as 
teachers cease interacting with the students relying upon limited amounts of feedback on assignments. The aspect of guiding reading development waned from the reading specialists' perspectives as students progress in grade levels despite the continued need for individualized instruction.

Technology utilization, or the lack thereof, was widely viewed as a contributing factor to students' negative attitudes towards reading. Becoming better technological facilitators and decision-makers is critical to advance literacy of all readers. Street (2005) furthers that the world is increasingly affected by new technologies as youth are discovering and also learning from outside the classroom. Yet, schools do not always value the knowledge that students gain from external sources compared to knowledge needed for scoring well on tests. The dichtomy between reading in school and literacies not valued in schools (Facebook, Twitter, blog, glog, chat) will continue to widen without additional research explorations on new literacies and their importance in the second decade of the $21^{\text {st }}$ century. All specialists agreed that using a range of student-selected pop culture and current events-related topics can provide a departure point for authentic communication as students use and develop literacy skills to discuss and debate topics and display various forms of expertise in areas that are meaningful and relevant to their achieved identities and social worlds (Knobel \& Lankshear, 2007). There is a need for educators to engage with and develop activities around media and popular culture that are central to students' lives and therefore improve students' attitudes towards reading.

Gee's (1997) discourse approach to literacies draws attention to the complexity and richness of the relationship between literacies and ways of being together in the world. Even video games can be informative as far as telling us about what learning could look like in the future. Students enjoy software games and investigating on the Internet because it provides opportunity for trial and error in an environment of little to no criticism or devaluation. Digital literacy skills should be explicitly taught alongside opportunities for reinforcement and practice in support of curricular objectives.

Effective usage of technology allows students to not only advance in their reading and writing, but also develop other essential literacies. Watts-Taffe, Gwinn, Johnson, and Horn (2003) purport:

Information and communication technologies (ICT) such as word processors, e-mail, CD-ROMs, digital video, and the Internet have changed the landscape of skills and competencies needed for workplace literacy in profound ways. In addition, workplace literacy requires the ability to access, interpret, compare and contrast, synthesize, and communicate ideas electronically. (p. 130)

Teachers are challenged not only to integrate technology with traditional aspects of literacy instruction (i.e., book reading and writing on paper) but also to engage students in emerging technological literacies (Leu, Mallette, \& Karchmer, 2001). According to the National Center for Education Statistics (2000), teacher preparation for technology integration is inadequate with most teachers reporting feeling ill prepared for utilizing technology in their instruction. 
Reading, from the struggling reader's perspective, is viewed differently than through Gee's lens, that literacies are social practices in order to associate them as socially recognized techniques of how things are done. According to Scribner and Cole (1981), "social practice" indicates the development and patterned ways of using technology socially and the knowledge needed to complete given tasks. In other words, literacy is applying this knowledge for specific purposes in specific contexts of use which can be described as a family of practices that include socially evolved and patterned activities.

The reality is that our students are being taught a variety of informational and communicative technologies that educators may not be familiar with or know how to operate or access. Specialists indicated that they had never blogged or sent instant messages. Some were willing to learn while others reported those activities were counterproductive and educators should not stoop to those low levels of communicative engagement with students.

\subsection{Limitations}

Researchers were aware of possible multiple interpretations among participants for a given sequence of events. There are inherent potential biases or systematic distortions in the subject's narratives (Klein \& Myers, 1999) and thus, inter-rater reliability along with data triangulation was utilized to minimize any bias or misrepresentation of data. The sample size of 10 reading specialists selected to interview along with only using specialists from one school district do not allow for generalizability.

\subsection{Implications}

Readers develop negative attitudes towards reading as the result of innumerable reasons but most notably from dreary experiences during their early reading education and adjustments in instructional delivery throughout grade levels. Classroom teachers must combat this trend by implementing reading strategies and providing more student-teacher interventions from early grades through junior high school. Too often, upper elementary and junior high teachers assume reading interventions are no longer needed when they could utilize a host of strategies such as graphic organizers and text structure of print and e-books.

Gee (1997) and Street (2005) suggest that teachers are using dated technologies such as worksheets with students who need educators to design valuable and significant curricula that incorporate options for the use of the new literacies. Oft times, the current resources in use actually contribute to the negative attitudes our students express when it comes to reading. Through further investigation into struggling students' perceptions about their negative attitudes towards reading, literacy educators can gain knowledge of factors contributing to this reading stance, and in turn, develop solutions to increase student's attitudes towards reading through the application of motivational reading strategies, interaction with students, and implementation of new technologies towards literacy development. 


\section{References}

Applegate, A., \& Applegate, M. D. (2010). A study of thoughtful literacy and motivation to read. The Reading Teacher, 64, 226-234. http://dx.doi.org/10.1598/RT.64.4.1

Baker, L. (2002). Metacognition in comprehension instruction. In C. C. Block \& M. Pressley (Eds.), Comprehension instruction: Research-based best practices (pp. 77-95). New York, NY: Guilford.

Baker, L., \& Wigfield, A. (1999). Dimensions of children's motivation for reading and their relations to reading activity and reading achievement. Reading Research Quarterly, 34, 452-477. http://dx.doi.org/10.1598/RRQ.34.4.4

Bandura, A. (1997). Self-efficacy: The exercise of control. New York, NY: W. H. Freeman

Berger, P. L., \& Luckmann, T. (1966). The social construction of reality. Garden City, NY: Doubleday.

Bhattacharya, K. (2007). Introduction to qualitative methods: A student handbook (week 3). Corpus Christi, TX Educational Administration and Research College of Education.

Block, C.C., Gambrell, L.B., \& Pressley, M. (Eds.). (2002). Improving comprehension instruction: Rethinking research, theory, and classroom practice. San Francisco, CA: Jossey-Bass.

Bontekoe, R. (1996). Dimensions of the hermeneutic circle. Atlantic Highlands, NJ: Humanities Press.

Brophy, J. (1999). Towards a model of the value aspects of motivation in education: Developing appreciation for particular learning domains and activities. Educational Psychologist, 34, 75-85. http://dx.doi.org/10.1207/s15326985ep3402_1

Crotty, M. (1998). The foundations of social research: Meaning and perspective in the research process. London, England: Sage.

Dilthey, W. (1972). The rise of hermeneutics. New Literary History, 3(2), 229-244. http://dx.doi.org/10.2307/468313

Edmunds, K. M., \& Bauserman, K. L. (2006). What teachers can learn about reading motivation through conversations with children. The Reading Teacher, 59(5), 414-424. http://dx.doi.org/10.1598/RT.59.5.1

Gambrell, L. (1996). Creating classroom cultures that foster reading motivation. The Reading Teacher, 50(1), 14-25.

Ganske, K., Monroe, J. K., \& Strickland, D. S. (2003). Questions teachers ask about struggling readers and writers. The Reading Teacher, 57(2), 118-128.

Gee, J. P. (1997). Thematized echoes. Journal of Narrative and Life History, 7, 189-196.

Guthrie, J. T., Coddington, C. S., \& Wigfield, A. (2009). Profiles of reading motivation 
among African American and Caucasian students. Journal of Literacy Research, 41(3), 317-356. http://dx.doi.org/10.1080/10862960903129196

Guthrie, J., \& Wigfield, A. (2000). Effects of integrated instruction on motivation and strategy use in reading. Journal of Educational Psychology, 92, 331-341. http://dx.doi.org/10.1037/0022-0663.92.2.331

Hughes, E.M., Brooker, H., Gambrell, L.B., \& Foster, V. (2011). Tutoring and mentoring: The results of an American Reads program on struggling readers' motivation and achievement. Association of Literacy Educators and Researchers Yearbook, Literacy Promises, 33, 205-218.

Ivey, G., \& Broaddus, K. (2001). “Just plain teaching”: A survey of what makes students want to read in middle school classrooms. Reading Research Quarterly, 36, 350-377. http://dx.doi.org/10.1598/RRQ.36.4.2

Johnson, B., \& Christensen, L. (2008). Educational Research: quantitative, qualitative and mixed methods (Third Edition). Thousand Oaks, CA: Sage.

Kamil, M.L. (2004). Vocabulary and comprehension instruction: Summary and implications of the National Reading Panel findings. In P. McCardle \& V. Chhabra (Eds.), The voice of evidence in reading research (pp. 213-234). Baltimore, MD: Paul H. Brooks Publishing.

Kinsella, E. A. (2006). Hermeneutics and critical hermeneutics: Exploring possibilities within the art of interpretation. Forum: Qualitative Social Research, 7(3). Retrieved from www.qualitative-research.net/index.php/fqs/article/view/145/319

Klein, H. K., \& Myers, M. D. (1999). A set of principles for conducting and evaluating interpretive field studies in information systems. MIS Quarterly, 23(1), 67-94. http://dx.doi.org/10.2307/249410

Knobel, M., \& Lankshear, C. (2007). A new literacies sampler. New York, NY: Peter Lang Publishing, Inc.

Leu, D. J., Mallette, M. H., \& Karchmer, R. A. (2001). New realities, new literacies, and new technologies: Redefining the agenda for literacy research. Reading Research and Instruction, 40(3), 265-272. http://dx.doi.org/10.1080/19388070109558349

Marinak, B. A., \& Gambrell, L B. (2010). Reading motivation: Exploring the elementary gender gap. Literacy Research and Instruction, 49(2), 129-141. http://dx.doi.org/10.1080/19388070902803795

McKeown, M. G., Beck, I. L., \& Blake, R. G. K. (2009). Rethinking reading comprehension instruction: A comparison of instruction for strategies and content approaches. Reading Research Quarterly, 44, 218-253. http://dx.doi.org/10.1598/RRQ.44.3.1

Morgan, P. L., \& Fuchs, D. (2007). Is there a bidirectional relationship between children's reading skills and reading motivation. Exceptional Children, 73(2), 242-255. 
http://dx.doi.org/10.1177/001440290707300203

National Institute of Child Health and Human Development. (2000). Report of the National Reading Panel. Teaching children to read: An evidence-based assessment of the scientific research literature on reading and its implications for reading instruction (NIH Publication No. 00-4769). Washington, DC: U.S. Government Printing Office.

Neufeld, P. (2006). Comprehension instruction in content area classes. The Reading Teacher, 59(4), 302-312. http://dx.doi.org/10.1598/RT.59.4.1

Nichols, J., Dagen, A.S., \& Rinehart, S. (2011). Text format, text comprehension, and related reader variables. Association of Literacy Educators and Researchers Yearbook, Literacy Promises, 33, 169-185.

No Child Left Behind: A Desktop Reference (2002). Washington, DC: Office of the Undersecretary. Available from http://ed.gov/offices/OESE/reference.html

Ortlieb, E. (2010). Beyond just books: Sparking students' interest in reading. International Journal of Education, 2(2), E9.

Ortlieb, E., Grandstaff-Beckers, G., \& Cheek, Jr., E. (2012). Fostering reading excellence at every level of school through reading clinics. The Clearing House, 85(1), 1-6. doi:10.1080/00098655.2011.601356

Pearson, P. D., \& Gallagher, M. C. (1983). The instruction of reading comprehension. Contemporary Educational Psychology, 8, 317-344. http://dx.doi.org/10.1016/0361-476X(83)90019-X

Pitcher, S., Albright, L., DeLaney, C., Walker, N., Seunarineingh, K., Mogge, S., Headley, K., \& Powers, W. G. (1981). The development of a reading avoidance measure. Reading Improvement, 18(4), 321-328.

Pressley, M. (2002). Reading instruction that works: The case for balanced teaching ( ${ }^{\text {nd }}$ ed.). New York, NY: Guilford.

Reis, S. M., McCoach, D. B., Little, C. A., Muller, L. M., \& Kaniskan, R. B. (2011). The effects of differentiated instruction and enrichment pedagogy on reading achievement in five elementary schools. American Education Research Journal, 48(2), 462-501. http://dx.doi.org/10.3102/0002831210382891

Schunk, D. H., \& Zimmerman, B. J. (1997). Developing self-efficacious readers and writers: The role of social and self-regulatory processes. In J. T. Guthrie \& A. Wigfield (Eds.), Reading engagement: Motivating readers through integrated instruction (pp. 34-50). Newark, DE: International Reading Association.

Schwandt, T. (2001). Hermeneutic circle. In T. Schwandt (Ed.), Dictionary of qualitative inquiry (pp. 112-118). Thousand Oaks, CA: Sage.

Scribner, S., \& Cole, M. (1981). The psychology of literacy. Cambridge, MA: Harvard University Press. http://dx.doi.org/10.4159/harvard.9780674433014 
Shank, G. D. (2006). Qualitative research: A personal skills approach ( $2^{\text {nd }}$ ed.) Upper Saddle River, NJ: Pearson Education, Inc.

Smith, J. K. (1983). Quantitative versus qualitative research: An attempt to clarify the issue. Educational Researcher, 12(3), 6-13. http://dx.doi.org/10.3102/0013189X012003006

Spradley, J. (1980). Participant observation. New York, NY: Holt, Rinehart \& Winston.

Stake, R. E. (1995). The art of case study research. Thousand Oaks, CA: Sage.

Stake, R. E. (2006). Multiple case study analysis. New York, NY: Guilford Press.

Stanovich, K. (1986). Matthew effects in reading: Some consequences of individual differences in the acquisition of literacy. Reading Research Quarterly, 21, 360-407. http://dx.doi.org/10.1598/RRQ.21.4.1

Street, B. (2005). Literacies across educational contexts: Mediating learning and teaching. Philadelphia, PA: Caslon Publishing.

Tovani, C. (2000). "I read it but I don't get it": Comprehension strategies for adolescentreaders. York, ME: Stenhouse.

U.S. Department of Education, Institute of Education Sciences, National Center for Education Statistics, National Assessment of Educational Progress (NAEP), various years, 1992-2011 Reading Assessments.

Vacca, R. T., \& Vacca, J. L. (2008). Content area reading (6 ${ }^{\text {th }}$ ed.). Boston, MA: Pearson Education, Inc.

Vaughn, S., Klinger, J., Swanson, E.A., Boardman, A.G., Roberts, G., Mohammed, S.S., \& Stillman-Spisak, S.J. (2011). Efficacy of collaborative strategic reading with middle school students. American Education Research Journal, 48(4), 938-964. http://dx.doi.org/10.3102/0002831211410305

Wasik, B.A. (1998). Volunteer tutoring programs in reading: A review. Reading Research Quarterly, 33, 266-291. http://dx.doi.org/10.1598/RRQ.33.3.2

Watts-Taffe, S., Gwinn, C. B., Johnson, J. R., \& Horn, M. L. (2003). Preparing preservice teachers to integrate technology with the elementary literacy program. The Reading Teacher, 57(2), 130-138.

Wigfield, A., \& Guthrie, J. T. (1997). Relations of children's motivation for reading to the amount and breadth of their reading. Journal of Educational Psychology, 89(3), 420-432. http://dx.doi.org/10.1037/0022-0663.89.3.420

Yin, R. K. (2002). Case study research: Design and methods ( $3^{\text {rd }}$ ed.). Thousand Oaks, CA: Sage. 


\section{Copyright Disclaimer}

Copyright reserved by the author(s).

This article is an open-access article distributed under the terms and conditions of the Creative Commons Attribution license (http://creativecommons.org/licenses/by/3.0/). 